\title{
Inner choroidal ischaemia and CNV due to handheld laser-induced maculopathy: a case report and review
}

\author{
Khoi $\operatorname{Tran}^{1} \cdot$ Derrick Wang ${ }^{1} \cdot$ Jackson Scharf ${ }^{1} \cdot$ SriniVas Sadda ${ }^{2} \cdot$ David Sarraf $^{1,3}$
}

Received: 3 October 2019 / Accepted: 18 December 2019 / Published online: 19 March 2020

(c) The Author(s), under exclusive licence to The Royal College of Ophthalmologists 2020

\begin{abstract}
There has been a sharp rise of reported handheld laser-induced maculopathy (HLIM) cases over the past decade, a concerning trend that may continue due to unregulated online access to high power lasers. Though HLIM has distinct clinical features, not uncommonly it may masquerade as other retinal disorders. It is critical therefore to recognise the clinical and multimodal imaging characteristics of this important and potentially devastating condition. As HLIM patients are typically young, unique issues need to be considered, such as delayed presentation, difficult history, poor compliance and behavioural or psychiatric comorbidity. This article will review the clinical and diagnostic features of laser injury, with a special emphasis on the multimodal retinal findings. In addition, we present a unique case of HLIM, resembling the presentation of a placoid disease variant and illustrating choroidal ischaemia using advanced retinal imaging, that offers further insight into the mechanisms of laser injury and its complications. The issues addressed in this review aim to increase recognition of an increasingly important and trending condition with potentially profound visual complications.
\end{abstract}

\section{Introduction}

Over the past several years, the incidence of handheld laserinduced maculopathy (HLIM) has been on the rise, a trend likely owing to increased access to high power lasers through online vendors [1-4]. According to the Food and Drug Administration (FDA), handheld laser pointers should emit a power of $<5 \mathrm{~mW}$ in order to minimise the risk of harm. However, the internet enables the purchase of much more powerful lasers, such as those capable of $1200 \mathrm{~mW}$ $[5,6]$. Furthermore, green lasers have grown in popularity and pose a greater risk to the retina due to their shorter wavelength compared with red lasers.

Macular injury from laser pointers is primarily encountered in adolescent males and results from both accidental

David Sarraf

dsarraf@ucla.edu

1 Department of Ophthalmology, Stein Eye Institute, University of California Los Angeles, Los Angeles, CA, USA

2 Department of Ophthalmology, Doheny Eye Institute, University of California Los Angeles, Los Angeles, CA, USA

3 Greater Los Angeles VA Healthcare Center, Los Angeles, CA, USA injury and intentional self-harm $[3,4,7]$. Not uncommonly, the patient may show reluctance admitting to the use of a laser. This can lead to a delay in diagnosis, especially since HLIM may resemble other macular diseases.

Patients with HLIM typically present with blurred vision, decreased visual acuity and central scotomas. The severity of symptoms and the prognosis for visual recovery largely depend on the extent of exposure, along with the laser's power and wavelength. Treatment for HLIM may include systemic corticosteroids, which are thought to reduce inflammation caused by the laser; however, the role of steroids remains a topic of debate due to variable outcomes. In most uncomplicated cases of HLIM, patients achieve near baseline vision within weeks to months with observation alone.

We review the current literature on this trending problem, discuss the mechanisms of laser injury and present a case offering unique insight into HLIM. Our case is distinct in that it is the first to demonstrate HLIM-associated choroidal ischaemia, leading to choroidal neovascularisation $(\mathrm{CNV})$ and masquerading as a placoid disease variant, such as persistent placoid maculopathy (PPM).

\section{Case presentation}

A 14-year-old male was referred for second opinion with progressive loss of central vision in the right eye. The 
Fig. 1 Colour fundus photographs of each eye at baseline presentation. a Colour fundus photograph of the right eye at baseline presentation illustrates a white plaque in the macula associated with a central pigment scar and vertical linear streaks typical of self-inflicted HLIM. Radiating inner retinal folds are also noted. b Colour fundus photograph of the left eye illustrates a large plaque of retinal whitening associated with vertical linear streaks at presentation.
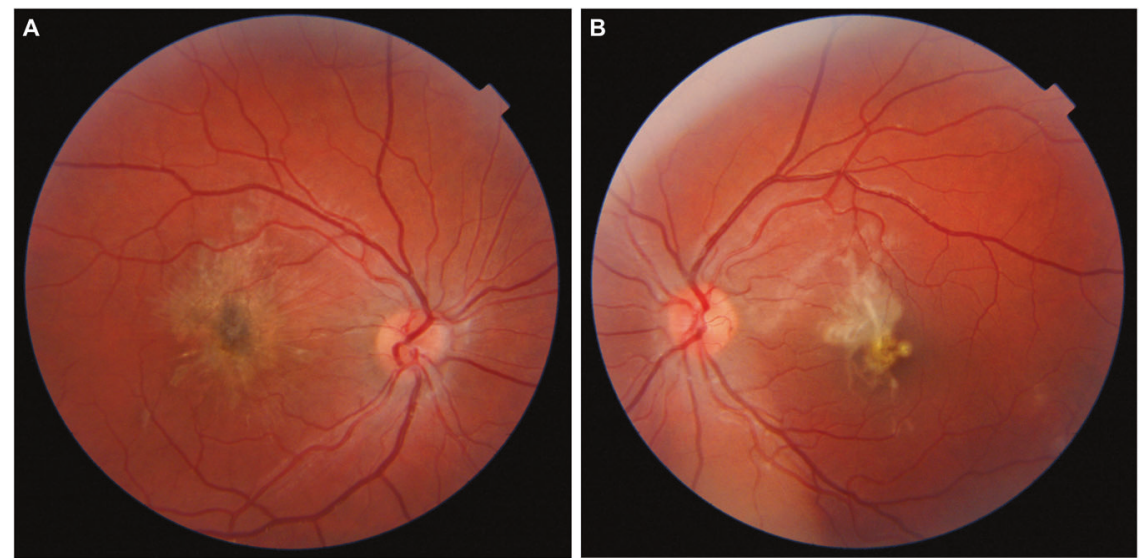

patient was initially observed, however, 4 weeks later he reported a pinpoint paracentral scotoma in the left eye. An inflammatory cause was suspected and the patient was started on oral Prednisone $60 \mathrm{mg}$ daily $(\sim 0.5 \mathrm{mg} / \mathrm{kg} /$ day) with subjective improvement in the right eye. After 3 weeks of steroid therapy, the dose was tapered to Prednisone $50 \mathrm{mg}$ daily, but a significant deterioration in central vision in the left eye developed 4 days prior to presentation.

The patient had recently discontinued alprazolam and started home schooling due to difficulties in school related to attention deficit hyperactivity disorder (ADHD). No other medications were noted and past medical, ocular and family history were otherwise unremarkable.

On presentation, visual acuity was count fingers both eyes (OU) and ophthalmic examination demonstrated an unremarkable anterior segment, lens and vitreous OU. Funduscopic examination of the right eye demonstrated a central plaque with vertical linear lesions emanating superior and inferior from the fovea and associated with a pigmented lesion and radial inner retinal folds (Fig. 1a). Left fundus examination showed a central plaque with superior curvilinear streaks (Fig. 1b).

Further questioning of the patient and his father was remarkable for an online purchase of a "military-grade" 5 $\mathrm{mW}$ green laser 3 months earlier. After initial denials, the patient eventually admitted to repetitive self-inflicted exposure to the right eye only. Father noted that the patient was playing with the laser in the days leading up to the recent deterioration of vision in the left eye.

Spectral domain OCT (SD-OCT) of the right macula demonstrated a central subretinal scar, retinal pigment epithelial (RPE) disruption and migration and disruption of the outer retina with attenuation of the ellipsoid zone, external limiting membrane and outer nuclear layer (Fig. 2c). SDOCT of the left macula illustrated typical findings of acute HLIM, namely, hyperreflective lesions extending radially in the Henle fibre layer (HFL) (Fig. 2d). Outer retinal disruption and RPE disruption were also noted.

Fundus autofluorescence (FAF) displayed central hypoautofluorescence bilaterally with hyperautofluorescence of the plaque edges and pathognomonic hyperautofluorescent linear vertical streaks, more prominent in the right eye (Fig. 3).

Both swept-source optical coherence tomography angiography and spectral domain optical coherence tomography angiography (SD-OCTA) illustrated large flow deficits in the choriocapillaris (CC) corresponding to the central lesions in each eye (Fig. 4) and consistent with inner choroidal ischaemia. CNV was noted inferotemporal to the fovea in the right eye within the region of choroidal nonperfusion (Fig. 4). Intravenous fluorescein angiography confirmed the presence of $\mathrm{CNV}$ in the right eye and demonstrated associated window defects confirming chronicity. The left eye showed remarkable hyperfluorescent vertical streaks throughout the posterior pole with mild leakage (Fig. 5).

Following detailed informed consent with the patient and his father, intravitreal aflibercept $2 \mathrm{mg} / 0.05 \mathrm{~mL}$ was administered to the right eye and was well tolerated under topical anaesthesia. At the 4-week follow-up visit, visual acuity remained unchanged at $\mathrm{CF}$ OU despite reported bilateral subjective improvement. SD-OCT of the left eye illustrated resolution of the HFL lesions with progression of outer retinal atrophy. SD-OCTA exhibited complete resolution of $\mathrm{CNV}$ in the right eye and improved perfusion of the inner choroid in both eyes (Fig. 6).

\section{Discussion}

In the United States, the safety level of laser devices is categorised and regulated according to the FDA and the American National Standard Institute. Most consumer laser 


\section{Fig. 2 Near-infrared}

reflectance and corresponding

SD-OCT images of each eye at baseline presentation. a Near-

infrared reflectance image of the right eye illustrates a central hyperreflective plaque associated with linear vertical streaks representing outer retinal disruption and fine radiating inner retinal folds. b Nearinfrared reflectance image of the left macula shows a central hyperreflective plaque with less distinct borders corresponding with early outer retinal alterations on SD-OCT B scan. c SD-OCT of the right macula illustrates a central

hyperreflective scar associated with intraretinal pigment migration (i.e., hyperreflective foci), loss of the outer retinal layers, but no evidence of fluid. d SD-OCT of the left macula in the acute phase of HLIM illustrates disruption of the outer retinal layers and radiating hyperreflective lesions in the Henle fibre layer.
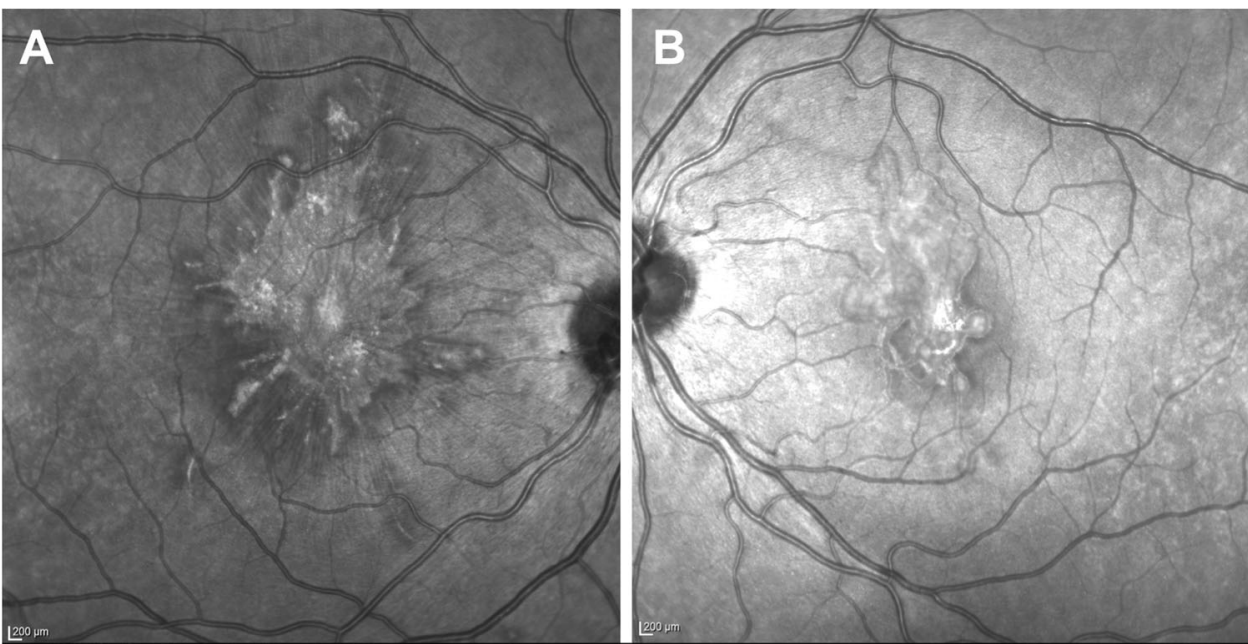

\section{C}

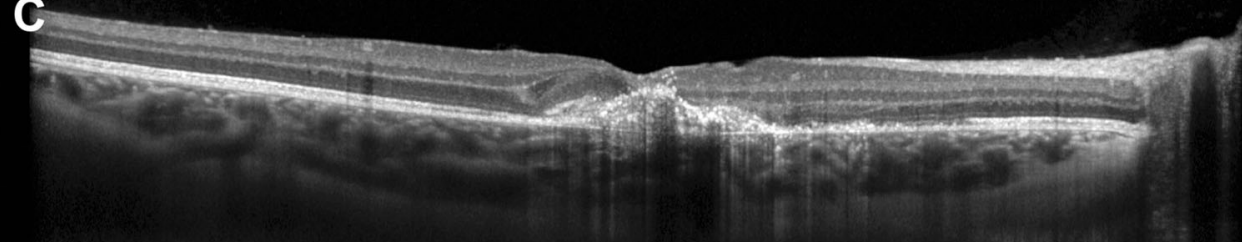

D

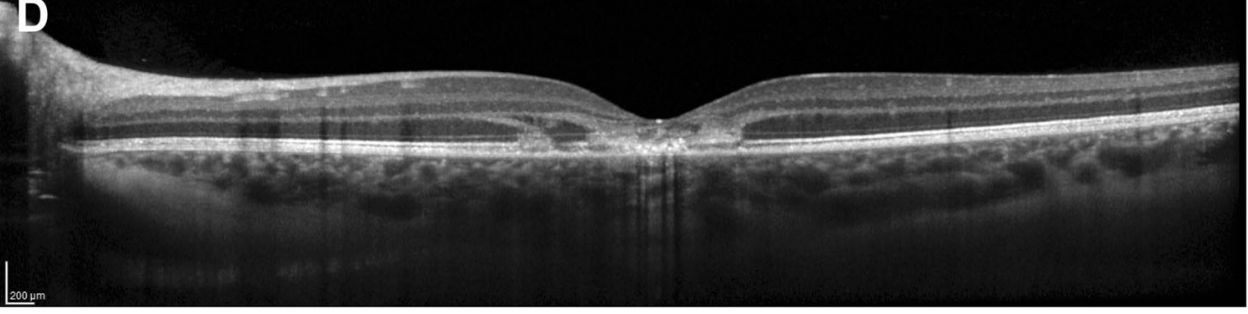

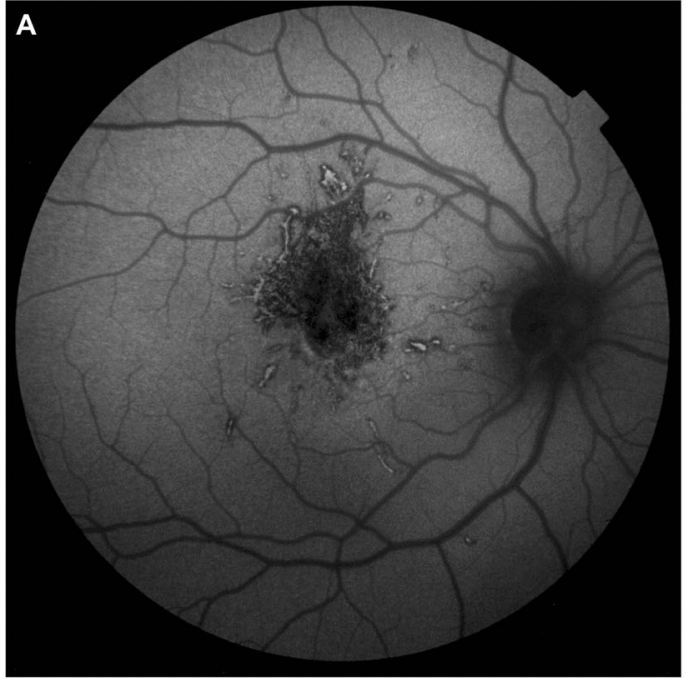

Fig. 3 Fundus autofluorescent images of the right and left eyes at baseline presentation. Fundus autofluorescent images illustrate hyperautofluorescence of the vertical streaks in each eye. Note the

pointers fall into class II or class IIIA level of safety, encompassing lasers in the visible light spectrum (400-700 $\mathrm{nm}$ ) with a power up to $5 \mathrm{~mW}$. At this level, accidental

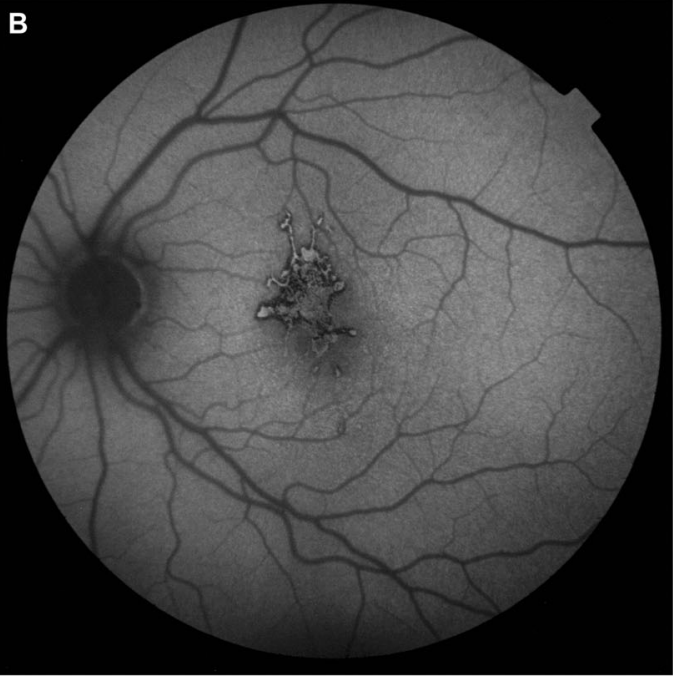

hypoautofluorescent atrophic central scar OD (a); and the hyperautofluorescent plaque central OS (b), indicating the outer retinal and RPE injury is more severe and longstanding in the right eye.

momentary exposure is deemed safe because it is terminated in $<0.25 \mathrm{~s}$ by the normal blink and aversion responses to uncomfortably bright light [8]. With more powerful 
Fig. 4 Swept-source en face OCTA and OCT images of each eye at presentation. Swept-source OCTA of the right (a) and left (b) eyes at the level of choriocapillaris illustrates large geographic areas of flow deficit corresponding to inner choroidal ischaemia and masquerading as a placoid variant. The registered OCT $\mathrm{B}$-scans show the corresponding level of segmentation. A CNV was noted inferotemporal to the fovea in the right eye within the area of choroidal nonperfusion
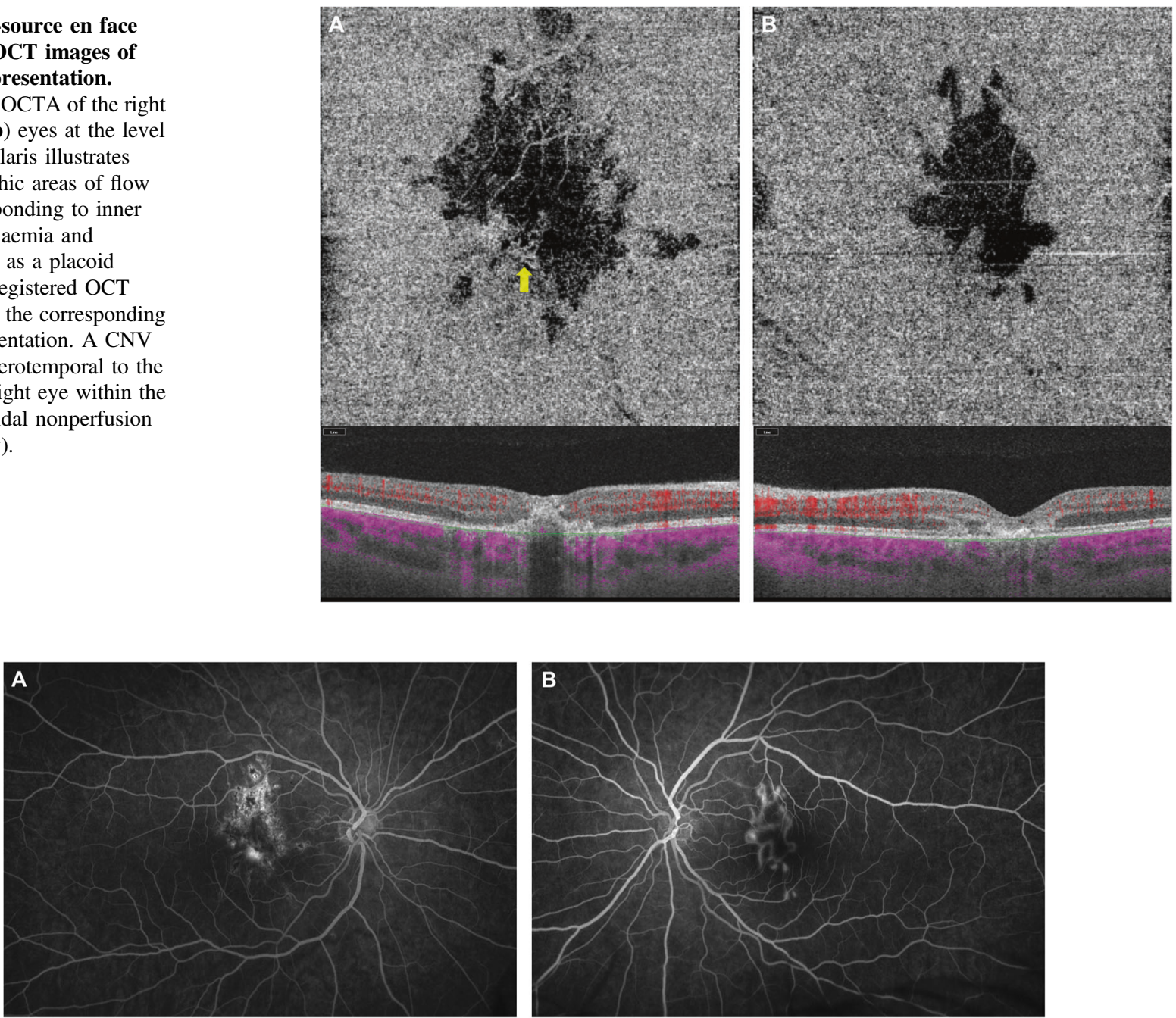

Fig. 5 Intravenous fluorescein angiography images of each eye at baseline presentation, demonstrating the unique differences between chronic and acute laser injury. a Intravenous fluorescein angiography (IVFA) of the right eye illustrates mottled fluorescent staining of the atrophic and fibrotic central scar. b IVFA of the left eye illustrates window defects corresponding to the remarkable hyperfluorescent streaks.

Fig. 6 En face SD-OCTA images and registered SDOCT B-scans of the right macula at baseline and following intravitreal aflibercept injection. Spectral domain-OCTA and OCT of the right macula at the level of the outer retina before (a) and after (b) aflibercept intravitreal injection OD. Note the complete resolution of the $\mathrm{CNV}$ and its flow signal on both the en face OCTA and the cross-sectional B scan overlay.
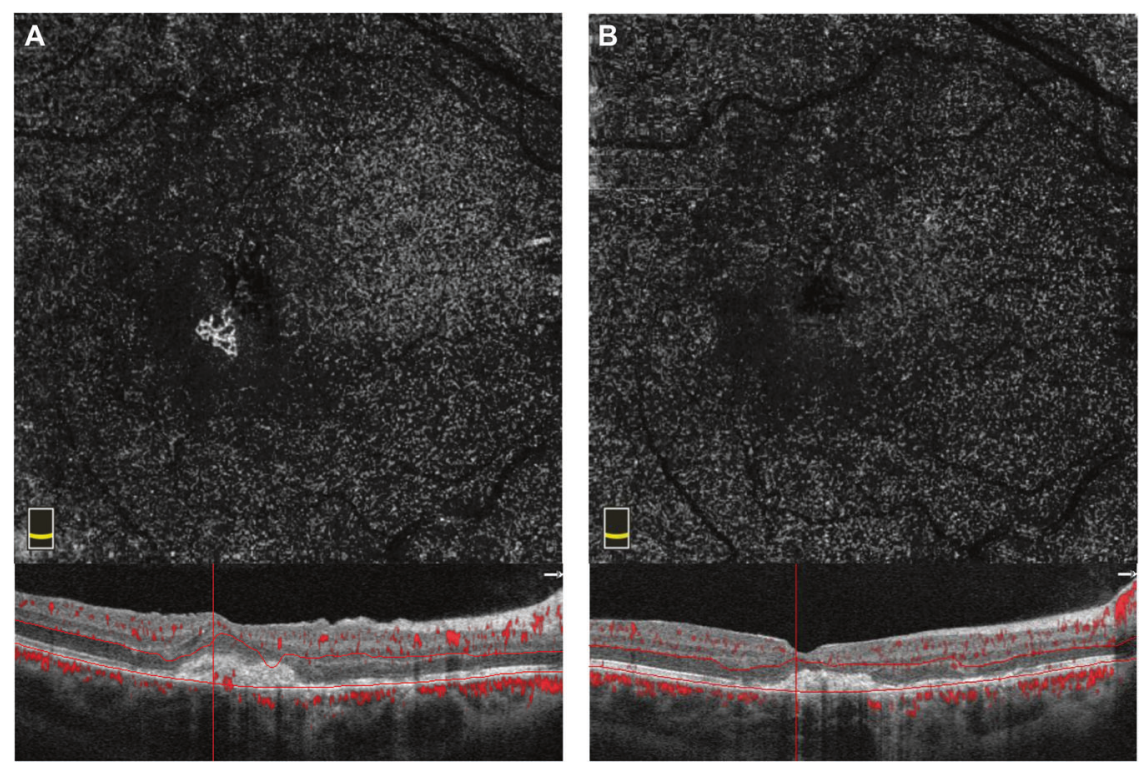
handheld lasers, either class IIIB $(5-500 \mathrm{~mW})$ or class IV $(>500 \mathrm{~mW})$, the natural protective mechanisms of the eye are ineffective and immediate retinal damage may occur, even after momentary exposure [5, 9-11]. Nevertheless, there continues to be a documented rise in reported HLIM injuries as devices become more powerful, increasingly accessible online, and less costly with lack of a regulatory body monitoring classification and labelling accuracy of handheld laser pointers $[1-4,11]$.

Our case of HLIM was notable for a remarkable large central area of inner choroidal flow deficit in each eye resembling inflammatory placoid disorders, such as PPM [12-14]. The area of choroidal ischaemia identified with OCTA can nicely explain the development of $\mathrm{CNV}$ which complicated the laser maculopathy in the right eye. CC hypoperfusion may be the result of direct photothermal injury to the RPE and inner choroid that may have been exacerbated by chronic repeated exposure to a high powered, short wavelength laser. An additional photochemical component may also have been a contributing factor $[8,11,15]$. It has been proposed that CC hypoperfusion in HLIM may develop secondary to RPE atrophy and the subsequent loss of their mutual symbiotic relationship [16]. However, the initial presence of the large CC flow void in the left eye, where significant RPE atrophy was not yet noted, demonstrates a more acute and direct process of choroidal injury and ischaemia.

In this patient, the geographic areas of CC signal void and secondary CNV, so nicely illustrated with OCTA, resembled inflammatory placoid conditions, such as PPM, relentless placoid chorioretinitis (RPC), macular serpiginous choroiditis and acute posterior multifocal placoid pigment epitheliopathy (APMPPE) [12-14, 17, 18]. The HFL radial lesions noted with OCT in our patient with HLIM have also been described in APMPPE [19-21]. However, the patient's age and history of selfinflicted laser combined with the typical clinical and multimodal imaging findings, including the bilateral vertical streaks best identified with FAF and fluorescein angiography, led to the diagnosis of HLIM. Other notable differences include the absence of peripheral lesions, often identified in RPC or APMPPE, and the lack of early hypofluorescence on intravenous FA observed with acute inflammatory placoid presentations [12-14, 17, 19, 22-24]. Given the overlapping features and the initial response to systemic corticosteroids, it is important to recognise HLIM in the differential diagnosis of placoid variant disorders, even in patients who deny laser exposure. Long-standing cases may be especially difficult to differentiate. It is interesting that inner choroidal ischaemia may be the primary underlying abnormality in both conditions, despite a vastly different inciting cause.
The acute and transient radial hyperreflective HFL lesions identified with SD-OCT may be noted in other diseases in addition to PPM and APMPPE. Henle hyperreflectivity is also a typical feature of acute macular neuroretinopathy, although both ischaemia of the deep retinal capillary plexus and the inner choroid have been implicated as pathogenic aetiologies [25-28]. Haemorrhages, exudates and pigment may also track in the HFL [19, 29-34].

With the ever-increasing frequency of HLIM, the spectrum of clinical and multimodal imaging findings is becoming more clearly defined [1, 2, 4, 7, 21, 35-37]. It is important to note that there are unique differences in the clinical presentation of self-inflicted versus accidental or peer-inflicted exposures $[1,7,21,35]$. As previously noted, self-inflicted HLIM often manifests with characteristic vertical streaks in the superior macula and acute retinal lesions radially oriented in the HFL with OCT. Patients with dark irides may additionally present with associated iris burns or atrophic lesions at the pupillary margin [38]. History of inadvertent laser play and behavioural or psychological conditions is not uncommon [3, 5, 7, 11]. Accidental exposures, however, have smaller discrete areas of outer retinal disruption and lack the linear vertical streaks $[1,3,4,7,11,21,35,38]$.

Progressive improvement with full visual and anatomical recovery is often reported. Clinical and OCT improvements may take place once the laser is removed and exposure has terminated and usually begins within the 7 days of injury [1]. The magnitude of reported improvement has been inconsistent, however, this is confounded by short and variable follow-up periods. Several reports with extended follow-up have demonstrated that both functional and structural rehabilitation continues for many months, indeed years following the injury $[2,10,11,39-41]$. Raoof et al. described a classification scheme based on presenting OCT features with milder HLIM injuries correlating with improved outcomes and better prognosis [4]. Predictably, more extensive injuries tended to have a delayed and protracted recovery with varying degrees of improvement [3, 4, 39]. Briefly, injuries graded as mild exhibited focal disruption of the outer retina and RPE [4]. Moderate injuries also displayed outer retinal and RPE damage, however, the findings were broader in nature. Severe injuries exhibited outer retinal atrophy and inner retinal hyperreflectivity [4]. However, this grading scheme failed to include many other complicating features associated with HLIM.

While many cases of HLIM result in satisfactory outcomes, more serious complications requiring intervention may include subretinal, intraretinal, subhyaloid and preretinal haemorrhage, full-thickness macular holes and CNV $[2,4,5,10,16,40-52]$. Several studies have exhibited HLIM-associated CC flow voids on either OCTA or ICGA, however, none have linked this finding to CNV formation, 
similar to the mechanisms proposed to explain the development of neovascularisation in advanced or late agerelated macular degeneration $[7,16,21,36,53,54]$. We propose that CNV formation in HLIM follows a similar path where significant loss of $\mathrm{CC}$ due to direct photothermal, photochemical and subsequent inflammatory injury leads to the release of VEGF and other angiogenic factors from ischaemic RPE to compensate for the $\mathrm{CC}$ hypoperfusion.

The paediatric population comprises $70-80 \%$ of reported HLIM cases [3, 4]. Since the first documented case by Fujinami, there have been few other reported paediatric cases of CNV due to HLIM [10, 39, 40, 44, 47, 55]. This may be due to the regenerative capabilities of the $\mathrm{CC}$ or the integrity of a younger, thinner Bruch's membrane modulating the inflammatory response $[36,56]$. An intact and younger BM may be able to support a more efficient RPE wound healing process following light or mechanical injury which may play a crucial role in the favourable recovery often encountered in HLIM patients [1, 39, 56]. Fortunately our patient was willing and cooperative to undergo intravitreal anti-VEGF therapy under topical anaesthesia. Considerations of sedation or general anaesthesia may need to be discussed with families of younger, less mature patients.

The role of systemic corticosteroids in the treatment of HLIM remains debated [2, 43, 57, 58]. Animal studies have shown that high dose methylprednisolone improves photoreceptor survival following laser injury to the retina. However, case reports of HLIM in humans have been associated with mixed results [2, 4, 10, 39, 59-61]. It has been postulated that steroid therapy may mitigate the inflammatory response caused by free radical formation and also reduces pigment migration induced by the laser, thereby hastening recovery and improving outcomes $[2,43,57,59]$. Despite the theoretical benefit of corticosteroids, treatment regimens and results vary in practice and positive outcomes remain confounded by the natural course of HLIM, which usually shows improvement with observation alone [4, 10, 37, 53].

Behavioural or psychiatric comorbidities may play a role in the occurrence of self-inflicted HLIM [1, 3, 7, 21, 38, 40, 44]. It has been proposed that those with ADHD and autism spectrum disorders (ASD) are at increased risk [3]. With marked impulsivity, a defining feature of ADHD, patients are thought to be more likely to engage in self-injurious behaviour (SIB) [3, 62]. Similarly, self-inflicted harm occurs frequently in patients with ASD [3]. The proclivity of patients with these diagnoses toward SIB likely predisposes them to HLIM if given access to high power lasers [3]. In our case, the patient presented with a diagnosis of ADHD and recent withdrawal of treatment medication possibly contributing to SIB and HLIM. The difficulty in extracting a confirmed history of exposure has been related to factitious disorder and is a further psychological consideration that can make diagnosis challenging [7]. The contribution of psychiatric comorbidities to HLIM remains understudied and underrecognised in the literature.

In summary, this report describes a case of HLIM in a paediatric patient who presented with clinical and imaging features resembling inflammatory placoid disease. This study provides further evidence that ocular damage from handheld lasers extends beyond the outer retina and causes $\mathrm{CC}$ injury. Consequently, secondary $\mathrm{CNV}$ formation may occur due to inner choroidal ischaemia. OCT angiography may provide an important practical tool to identify choroidal ischaemia and CNV formation and together with OCT and FAF and FA, is critical to accurately diagnose HLIM and its masquerade presentations, monitor progression and response to therapy, and provide prognostication. With a rising incidence of HLIM cases and easy accessibility to high-powered handheld lasers via the internet, immediate recognition of HLIM is crucial to avert continuing retinal and choroidal damage and prevent blindness.

\section{Compliance with ethical standards}

Conflict of interest Research to Prevent Blindness Inc (DS), New York NY and Macula Foundation Inc (DS) New York, NY.

Publisher's note Springer Nature remains neutral with regard to jurisdictional claims in published maps and institutional affiliations.

\section{References}

1. Dhrami-Gavazi E, Lee W, Balaratnasingam C, Kayserman L, Yannuzzi LA, Freund KB. Multimodal imaging documentation of rapid evolution of retinal changes in handheld laser-induced maculopathy. Int J Retin Vitr. 2015;1:14.

2. Mtanes K, Mimouni M, Zayit-Soudry S. Laser pointer-induced maculopathy: more than meets the eye. J Pediatr Ophthalmol Strabismus. 2018;55:312-8.

3. Linton E, Walkden A, Steeples LR, Bhargava A, Williams C, Bailey $\mathrm{C}$, et al. Retinal burns from laser pointers: a risk in children with behavioural problems. Eye (Lond). 2019;33:492-504.

4. Raoof N, Bradley P, Theodorou M, Moore AT, Michaelides M. The new pretender: a large UK case series of retinal injuries in children secondary to handheld lasers. Am J Ophthalmol. 2016;171:88-94.

5. Alsulaiman SM, Alrushood AA, Almasaud J, Alzaaidi S, Alzahrani Y, Arevalo JF, et al. High-power handheld blue laser-induced maculopathy: the results of the King Khaled Eye Specialist Hospital Collaborative Retina Study Group. Ophthalmology. 2014;121:566-72. e1.

6. US Food \& Drug Administraiton. Important information for laser pointer manufacturers. 2015. https://www.fda.gov/radiationemitting-products/laser-products-and-instruments/importantinformation-laser-pointer-manufacturers. Accessed 2019.

7. Rabiolo A, Sacconi R, Giuffre C, Corbelli E, Carnevali A, Querques L, et al. Self-Inflicted laser handheld laser-induced maculopathy: a novel ocular manifestation of factitious disorder. Retin Cases Brief Rep. 2018;12(Suppl 1):S46-50. 
8. Mainster MA, Stuck BE, Brown J Jr. Assessment of alleged retinal laser injuries. Arch Ophthalmol. 2004;122:1210-7.

9. Laser Institute of America. American National Standard for Safe Use of Lasers Z136.1. Orlando, FL: Laser Institute of America; 2014.

10. Xu K, Chin EK, Quiram PA, Davies JB, Parke DW III, Almeida DR. Retinal injury secondary to laser pointers in pediatric patients. Pediatrics. 2016;138:e20161188.

11. Lee GD, Baumal CR, Lally D, Pitcher JD, Vander J, Duker JS. Retinal injury after inadvertent handheld laser exposure. Retina. 2014;34:2388-96.

12. Dolz-Marco R, Sarraf D, Giovinazzo V, Freund KB. Optical coherence tomography angiography shows inner choroidal ischemia in acute posterior multifocal placoid pigment epitheliopathy. Retin Cases Brief Rep. 2017;11:S136-43.

13. Klufas MA, Phasukkijwatana N, Iafe NA, Prasad PS, Agarwal A, Gupta V, et al. Optical coherence tomography angiography reveals choriocapillaris flow reduction in placoid chorioretinitis. Ophthalmol Retina. 2017;1:77-91.

14. Sassalos TM, Saraf SS, Ober MD. Chorioretinal perfusion in persistent placoid maculopathy. Ophthalmic Surg Lasers Imaging Retina. 2017;48:1026-31.

15. Marshall J. The safety of laser pointers: myths and realities. Br J Ophthalmol. 1998;82:1335-8.

16. Clemente-Tomas R, Bayo-Calduch P, Neira-Ibanez P, GargalloBenedicto A, Duch-Samper AM. Bilateral maculopathy after exposure to a laser pointer: optical coherence tomography angiography findings. Arch Soc Esp Oftalmol. 2018;93:551-4.

17. Gendy MG, Fawzi AA, Wendel RT, Pieramici DJ, Miller JA, Jampol LM. Multimodal imaging in persistent placoid maculopathy. JAMA Ophthalmol. 2014;132:38-49.

18. Furino C, Shalchi Z, Grassi MO, Cardoso JN, Keane PA, Niro A, et al. OCT Angiography in acute posterior multifocal placoid pigment epitheliopathy. Ophthalmic Surg Lasers Imaging Retina. 2019;50:428-36.

19. Mrejen S, Sarraf D, Chexal S, Wald K, Freund KB. Choroidal involvement in acute posterior multifocal placoid pigment epitheliopathy. Ophthalmic Surg Lasers Imaging Retina. 2016;47:20-6.

20. Goldenberg D, Habot-Wilner Z, Loewenstein A, Goldstein M. Spectral domain optical coherence tomography classification of acute posterior multifocal placoid pigment epitheliopathy. Retina. 2012;32:1403-10.

21. Combillet F, Saunier V, Rougier MB, Delyfer MN, Korobelnik JF. Multimodal imaging in a case of self-inflicted laser-induced maculopathy. Eur J Ophthalmol. 2016;26:e155-7.

22. Maggio E, Alfano A, Polito A, Pertile G. Choroidal perfusion abnormalities associated with acute posterior multifocal placoid pigment epitheliopathy: a case report. BMC Ophthalmol. 2018; $18: 87$

23. Wang JC, Lains I, Sobrin L, Miller JB. Distinguishing white dot syndromes with patterns of choroidal hypoperfusion on optical coherence tomography angiography. Ophthalmic Surg Lasers Imaging Retina. 2017;48:638-46.

24. Golchet PR, Jampol LM, Wilson D, Yannuzzi LA, Ober M, Stroh E. Persistent placoid maculopathy: a new clinical entity. Ophthalmology. 2007;114:1530-40.

25. Thanos A, Faia LJ, Yonekawa Y, Randhawa S. Optical coherence tomographic angiography in acute macular neuroretinopathy. JAMA Ophthalmol. 2016;134:1310-4.

26. Casalino G, Arrigo A, Romano F, Munk MR, Bandello F, Parodi MB. Acute macular neuroretinopathy: pathogenetic insights from optical coherence tomography angiography. $\mathrm{Br} \mathrm{J}$ Ophthalmol. 2019;103:410-4.

27. Nemiroff J, Sarraf D, Davila JP, Rodger D. Optical coherence tomography angiography of acute macular neuroretinopathy reveals deep capillary ischemia. Retin Cases Brief Rep. 2018;12: S12-5.

28. Lee SY, Cheng JL, Gehrs KM, Folk JC, Sohn EH, Russell SR, et al. Choroidal features of acute macular neuroretinopathy via optical coherence tomography angiography and correlation with serial multimodal imaging. JAMA Ophthalmol. 2017; 135:1177-83.

29. Fawzi AA, Pappuru RR, Sarraf D, Le PP, McCannel CA, Sobrin L, et al. Acute macular neuroretinopathy: long-term insights revealed by multimodal imaging. Retina. 2012;32:1500-13.

30. Au A, Hou K, Baumal CR, Sarraf D. Radial hemorrhage in henle layer in macular telangiectasia type 2. JAMA Ophthalmol. 2018;136:1182-5.

31. Curcio CA, Zanzottera EC, Ach T, Balaratnasingam C, Freund $\mathrm{KB}$. Activated retinal pigment epithelium, an optical coherence tomography biomarker for progression in age-related macular degeneration. Invest Ophthalmol Vis Sci. 2017;58:BIO211-26.

32. Michel Z, Redd T, Bhavsar KV. Multimodal imaging of two unconventional cases of bartonella neuroretinitis. Retin Cases Brief Rep. 2019. https://doi.org/10.1097/ICB.0000000000000893. [Epub ahead of print].

33. Abdelhakim A, Rasool N. Neuroretinitis: a review. Curr Opin Ophthalmol. 2018;29:514-9.

34. Habot-Wilner Z, Zur D, Goldstein M, Goldenberg D, Shulman S, Kesler A, et al. Macular findings on optical coherence tomography in cat-scratch disease neuroretinitis. Eye (Lond). 2011;25:1064-8.

35. Bhavsar KV, Wilson D, Margolis R, Judson P, Barbazetto I, Freund KB, et al. Multimodal imaging in handheld laser-induced maculopathy. Am J Ophthalmol. 2015;159:227-31. e2.

36. Tomasso L, Benatti L, La Spina C, Lattanzio R, Baldin G, Carnevali A, et al. Optical coherence tomography angiography findings in laser maculopathy. Eur J Ophthalmol. 2017;27:e13-5.

37. Weng CY, Baumal CR, Albini TA, Berrocal AM. Self-induced laser maculopathy in an adolescent boy utilizing a mirror. Ophthalmic Surg Lasers Imaging Retina. 2015;46:485-8.

38. Dolz-Marco R, Cunha Souza E, Iida T, Moreira CA, Jr., Nakashima A, Hasegawa $T$, et al. Iris atrophy: a novel sign of repeated self-inflicted laser pointer maculopathy. Retina. 2017;37:26-8.

39. Chen X, Dajani OAW, Alibhai AY, Duker JS, Baumal CR. Longterm visual recovery in bilateral handheld laser pointer-induced maculopathy. Retin Cases Brief Rep. 2019. https://doi.org/10. 1097/ICB.0000000000000845. [Epub ahead of print].

40. Forshaw TRJ, Sorensen TL, Munch IC. Accidental macular laser burn in a 12-year-old boy complicated with choroidal neovascularization: 4-year follow-up with spectral-domain optical coherence tomography. Acta Ophthalmol. 2018;96:e899-901.

41. Qi Y, Wang Y, You Q, Tsai F, Liu W. Surgical treatment and optical coherence tomographic evaluation for accidental laserinduced full-thickness macular holes. Eye. 2017;31:1078-84.

42. Chang CY, Sheu SJ. Choroidal neovascularization secondary to intense pulsed light injury. Ophthalmic Plast Reconstr Surg. 2018;34:e129-31.

43. Chen YY, Lu N, Li JP, Yu J, Wang L. Early treatment for laserinduced maculopathy. Chin Med J. 2017;130:2121-2.

44. Fujinami K, Yokoi T, Hiraoka M, Nishina S, Azuma N. Choroidal neovascularization in a child following laser pointer-induced macular injury. Jpn J Ophthalmol. 2010;54:631-3.

45. Sun Z, Wen F, Li X, Wu D. Early subfoveal choroidal neovascularization secondary to an accidental stage laser injury. Graefes Arch Clin Exp Ophthalmol. 2006;244:888-90.

46. Veronese C, Maiolo C, Huang D, Jia Y, Armstrong GW, Morara $\mathrm{M}$, et al. Optical coherence tomography angiography in pediatric choroidal neovascularization. Am J Ophthalmol Case Rep. 2016;2:37-40. 
47. Raoof N, Chan TK, Rogers NK, Abdullah W, Haq I, Kelly SP, et al. 'Toy' laser macular burns in children. Eye (Lond). 2014;28:231-4.

48. Porrua L, Oblanca N, Gonzalez-Lopez JJ. Spontaneous closure of a blue laser induced full thickness macular hole. Arch Soc Esp Oftalmol. 2017;92:29-32.

49. Androudi S, Papageorgiou E. Macular hole from a laser pointer. $\mathrm{N}$ Engl J Med. 2018;378:2420.

50. Nelson LB. Macula damage from laser pointers. J Pediatr Ophthalmol Strabismus. 2018;55:287.

51. Dhoot DS, Xu D, Srivastava S. High-powered laser pointer injury resulting in macular hole formation. J Pediatr. 2014;164:668.e661.

52. Petrou P, Patwary S, Banerjee PJ, Kirkby GR. Bilateral macular hole from a handheld laser pointer. Lancet. 2014;383:1780.

53. Turaka K, Bryan JS, Gordon AJ, Reddy R, Kwong HM Jr., Sell $\mathrm{CH}$. Laser pointer induced macular damage: case report and mini review. Int Ophthalmol. 2012;32:293-7.

54. Sherif M, Berthoud J, Pournaras JA, Ambresin A. OCTangiography as a help in the diagnosis of a laser pointer retinal injury: a case report. Klin Monbl Augenheilkd. 2019;236:594-7.

55. Wyrsch S, Baenninger PB, Schmid MK. Retinal injuries from a handheld laser pointer. N Engl J Med. 2010;363:1089-91.
56. Booij JC, Baas DC, Beisekeeva J, Gorgels TG, Bergen AA. The dynamic nature of Bruch's membrane. Prog Retin Eye Res. 2010;29:1-18.

57. Alda J, Gomez Sanz F, Gonzalez Martin-Moro J. Laser pointer maculopathy. A new public health problem? Arch Soc Esp Oftalmol. 2017;92:1-3.

58. Hossein M, Bonyadi J, Soheilian R, Soheilian M, Peyman GA. SD-OCT features of laser pointer maculopathy before and after systemic corticosteroid therapy. Ophthalmic Surg Lasers Imaging. 2011;42:e135-8.

59. Barkana Y, Belkin M. Laser eye injuries. Surv Ophthalmol. 2000;44:459-78.

60. Brown J Jr., Hacker H, Schuschereba ST, Zwick H, Lund DJ, Stuck BE. Steroidal and nonsteroidal antiinflammatory medications can improve photoreceptor survival after laser retinal photocoagulation. Ophthalmology. 2007;114:1876-83.

61. Robertson DM, McLaren JW, Salomao DR, Link TP. Retinopathy from a green laser pointer: a clinicopathologic study. Arch Ophthalmol. 2005;123:629-33.

62. American Psychiatric Association. Diagnostic and statistical manual of mental disorders. Washington, DC: American Psychiatric Association; 2013. 